\title{
Deber moral y economía en las teodiceas de Leibniz y Malebranche
}

\author{
Carlos Velasco
}

Mestre em Estudos Históricos Avançados pela Universidade de Sevilla e em Filosofia Teórica e Prática pela Universidad Nacional de Educación a Distancia (UNED)

\section{Resumen}

El artículo realiza un acercamiento a las teodiceas de Leibniz y de Malebranche centrándose en los conceptos de "deber moral” y "economía”. A partir de aquí se calibran los términos bajo los cuales ambos filósofos entienden la libertad divina, así como la cantidad de bien que debe derivarse de la racionalidad a la que Dios se somete cuando crea el mundo. El modelo leibniciano será estudiado a la luz de los retos que, desde perspectivas polarizadas, plantearon autores como Hobbes y Spinoza a la disyunción entre la absoluta trascendencia de Dios a su creación y la subsunción de la divinidad a prescripciones lógico-metafísicas. Se destaca que el rigor conceptual de Malebranche y la esencia económica que postula para la divinidad se concilian con una concepción filosófica e histórica netamente cristiana en la que la racionalidad pura se remite a fundamentos teológicos.

Palabras Clave Teodicea - Deber moral - Economía - Voluntad divina - Principio de razón suficiente - Principio de identidad.

\section{Resumo}

$\mathrm{O}$ artigo realiza uma aproximação às teologias de Leibniz e Malebranche centrando-se nos conceitos de "dever moral" e "economia". Com base nisso, examina-se os termos a partir dos quais os dois filósofos entendem a liberdade divina, bem como a quantidade de bem que deve se derivar da racionalidade à qual Deus se submete ao criar o mundo. O modelo leibniciano será estudado à luz das questões que, em perspectivas opostas, autores como Hobbes e Spinoza se colocaram sobre a disjunção entre a absoluta transcendência de Deus, a sua criação e a subsunção da divindade a prescrições lógico-metafísicas. Destaca-se que o rigor conceitual de Malebranche e a essência econômica que ele postula para a divindade se conciliam com uma concepção filosófica e histórica claramente cristã, na qual a racionalidade pura remete a fundamentos teológicos.

Palavras-chave Teodicéia - Dever moral - Economia - Vontade divina - Princípio da razão suficiente - Princípio da identidade.

\section{Submissão}

13/03/2020 Aprovação

25/06/2020 Publicação

$\mathrm{I} 2 / 08 / 2020$ 


\section{Introducción}

$\mathrm{L}$ a teodicea de Leibniz se enmarca en el difícil propósito de hacer conciliable la independencia absoluta de la naturaleza, concebida como un mecanicismo autónomo, con la libertad irrestricta del Creador. El filósofo de Hannover trata así de apuntalar una vía intermedia entre los dos grandes partidos que capitalizaban el debate filosófico a la sazón: el fatalismo o la necesidad ciega, de un lado, que, tradicionalmente defendido por epicúreos, estoicos y pirrónicos, había encontrado una nueva versión en la metafísica spinozista, y el voluntarismo teológico ${ }^{1}$, que propugnaba que la voluntad de Dios es completamente indiferente e inasible para los hombres, primando así las cuestiones de gracia sobre las cuestiones de razón. Leibniz desarrolló sus pensamientos en un contexto histórico marcado por los conflictos confesionales dentro del cristianismo, frente al cual trataría—en vano-de desarrollar el proyecto de una Europa unida. Es importante no soslayar este elemento cuando se trata de comprender su teodicea: la subordinación y superación de la miríada de dogmas teológicos en un sistema universalmente comprensible a través de la razón y reducible a unos cuantos preceptos matemáticos y geométricos está en total congruencia con este proyecto de consecución de un lenguaje universalmente válido que superara el encastillamiento dogmático de los distintos dogmas confesionales, que había conducido al continente a interminables conflictos.

Malebranche también intenta abrir con sus ideas un camino entre dos posiciones polarizadas. Por un lado, se opone al fideísmo absoluto y a la gracia eficaz del partido jansenista (que tuvo en B. Pascal, A. Arnauld y P. Quesnel sus cabezas de fila más granados); por otro, al voluntarismo ciego de Hobbes, que postulaba a la divinidad esencialmente inadecuada a cualesquiera proposiciones racionales. Su edificio intelectual persevera en el desarrollo de la física y la metafísica cartesianas, mas poniendo término a la propensión hacia la autonomía del cogito y las ideas innatas al reconvenir ambas agencias en la dependencia de Dios. De este modo, los avances de la filosofía moderna hallaban encaje en el ethos cristiano al tiempo que el cristianismo y su nuevo prototipo de Dios sabio y sumamente inteligente se situaba como principio y fin del proceso de ilustración.

I MORMINO, G. Determinismo e utillitarismo nella teodicea di Leibniz. Milán: Franco Angeli, 2005, pp. 176-177.

$316 \bullet$ ano XI, n. 16, 2020 • ISSN 2179-5487 


\section{El papel del “deber moral” en la teodicea leibniciana}

Los grandes especialistas en Leibniz aciertan a distinguir dos elementos quiciales en su metafísica. De un lado, el principio de identidad o contradicción introduce que, cuando nos encontramos con dos proposiciones contradictorias, ha de seguirse que la una es verdadera y la otra es falsa. Este precepto es válido para el ámbito de las esencias, y supone una necesidad absoluta que Leibniz denomina también lógica, metafísica y geométrica. El segundo gran axioma del sistema leibniciano es el de razón suficiente. Éste supone una necesidad moral a la que denomina también física o hipotética. Su campo de operatividad es el de la física, teología natural, metafísica y moral².

Estas dos leyes concurren de manera decisiva en la fundación del sistema de su teodicea, como el mismo autor nos adelanta al inicia de su obra homónima:

Las verdades de la razón son de dos clases. Unas se llaman verdades eternas, y son absolutamente necesarias, de manera que lo opuesto implica contradicción, tales como aquella cuya necesidad es lógica, metafísica o geométrica, y que no es posible negar sin caer en el absurdo. Hay otras que se pueden llamar verdades positivas, porque son las leyes que Dios ha tenido a bien dar a la naturaleza, o porque dependen de él (...) la elección libre de Dios, y no una necesidad geométrica, es la que hace preferible lo conveniente y le da existencia. Y así, puede decirse que la necesidad física se funda en la necesidad moral, es decir, en la elección del sabio digna de su sabiduría3.

Este extracto epitoma el espíritu que va a presidir la teodicea leibniciana. Dios ha creado el mundo de acuerdo con un criterio de razón, lo que implica que no es posible encontrar contradicción alguna en su obra, que no diferiría de las leyes de la lógica, la geometría o las matemáticas. Sin embargo, en el curso de su acción creadora, Dios no se habría visto impelido por una necesidad conceptual o metafísica, sino que habría actuado libremente. La vigencia de las leyes de la lógica no debe redundar en ningún caso en detrimento de la libertad divina. Y es que este corolario habría aproximado el sistema leibniciano a los postulados de la metafísica materialista y panteísta de Spinoza, para quien "todo lo que existe, existe necesariamente, y lo que no existe no puede existir, mientras que para el filósofo de Hannover lo que sucede podría haber sucedido de un modo diferente" ${ }^{4}$.

2 FERNÁNDEZ-GARCÍA, Ma . La omnipotencia del Absoluto en Leibniz. Barañáin (Navarra): Ediciones Universidad de Navarra, 2000, pp. I39-I42.

3 LEIBNIZ, G. W. Teodicea: ensayos sobre la bondad de Dios, la libertad del hombre y el origen del mal (Edición Digital a cargo de Jacobo Muñoz). Madrid: Biblioteca Nueva, 20I4. pp. 73-74.

4 ISRAEL, J. La Ilustración radical: La filosofía y la construcción de la Modernidad, I650-1750. México D.F.: FCE, 2012, p. 633. 


\section{REVISTA ANGELUS NOVUS}

El mundo existente es el mejor de los mundos posibles no por una causación ciega de la naturaleza, sino porque Dios, en el amplio espectro de mundos que pudo haber creado a causa de su inobjetable libertad, así lo resolvió, de acuerdo con la bondad y sabiduría que se han de postular como consustanciales al mejor de los seres imaginables. Ahora bien, si escrutamos la naturaleza y sus leyes físicas prima facie, el mundo y el universo bien podría presentársenos en los términos que lo entiende Spinoza: hay una necesidad absoluta de "verdades eternas", tales como las de la geometría, que son conceptual y eternamente inalterables. Ante estas objeciones responderá Leibniz que, si el mundo se parece más a la red causal inamovible de leyes naturales discernibles a través de la geometría y la matemática, tal como preconizó Spinoza, esto se debería a que Dios, en contra de lo que sostenía Hobbes, actúa en consonancia con unos patrones conceptuales predeterminados. Ahora bien, el que Dios actuara de esta manera no mina ni compele su libertad en absoluto: actúa de acuerdo con la idea de sabiduría y bondad adscritas a él porque es un "ser moral", no por una necesidad ciegas. Con la distinción entre la "necesidad absoluta" de causa y efecto mecánicos (estrechamente relacionada con la filosofía de Spinoza) y la "necesidad moral" de Dios de elegir siempre la mejor de las posibilidades existentes, Leibniz se mostró confiado en haber rescatado el libre albedrío de Dios al tiempo que afirmaba la predictibilidad y regularidad absoluta de las leyes de la naturaleza tal como las concebía la ciencia moderna de su tiempo ${ }^{6}$.

Leibniz nos consigna una descripción más precisa de la particular concatenación de voluntad y sabiduría en su sistema en el parágrafo 7 de la Théodicée:

El poder se encamina al ser, la sabiduría o el entendimiento a lo verdadero, y la voluntad al bien. Y esta causa inteligente debe ser infinita en todos conceptos, y absolutamente perfecta en poder, en sabiduría y en bondad, puesto que alcanza a todo lo que es posible. Y como todo se liga, no da lugar a admitir más que una. Su entendimiento es el origen de las esencias, y su voluntad es el origen de las existencias. He aquí en pocas palabras la prueba de un Dios único con sus perfecciones, y por su medio el origen de las cosas?.

Trataremos de arrojar luz acerca del peculiar concepto que Leibniz maneja de la voluntad divina a través de la controversia que mantuvo a este tenor con Hobbes. El

5 Sobre este punto se pronunció en el parágrafo 345 de la Theodicée (LEIBNIZ, G. W. Madrid: Biblioteca Nueva, 20I4, p. 328): "No nacen ellas [las leyes de la naturaleza] enteramente del principio de la necesidad, sino que nacen del principio de la perfección y del orden, como que son un efecto de la elección y la sabiduría de Dios. Puedo demostrar estas leyes de muchas maneras, pero siempre es preciso suponer algo que no es de una necesidad absolutamente geométrica. De manera que estas preciosas leyes son una prueba maravillosa de la existencia de un ser inteligente y libre contra el sistema de Estratón o de Spinoza”.

6 ISRAEL, J., 2012, opus cit., pp. 636-637.

7 LEIBNIZ, G. W. Teodicea: ensayos sobre la bondad de Dios, la libertad del hombre y el origen del mal. (Edición digital a cargo de Jacobo Muñoz). Madrid: Biblioteca Nueva, 20I4, p. I2I.

$318 \bullet$ ano XI, n. 16, 2020 • ISSN 2179-5487 
filósofo inglés afirmaba que "no tenemos ninguna idea que pueda proporcionarnos una representación positiva de Dios. Éste no es solamente incomprensible, sino también

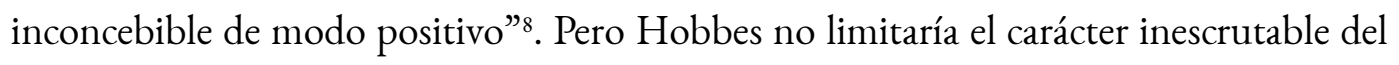
creador al dominio de la epistemología, sino que lo amplificaría al de la causalidad física que vimos a Leibniz cimentar sobre su precepto de razón suficiente. Dios-al decir de Hobbes- sería en si en el sentido de "sin causa”, es decir, completamente inadecuado e indiferente a la categoría de casualidad, toda vez que dicha categoría fue forjada para el conocimiento del mundo. La absoluta trascendencia de Dios respecto al mundo que se colige de estos postulados culmina en el célebre apotegma hobbesiano que dice que el único enunciado que puede convenir a Dios es que "existe". "El único nomem proprium de Dios es est quod est". Se sigue de todo esto, como Zarka ${ }^{\text {10 }}$ advierte de manera lúcida, que "la trascendencia absoluta de Dios no sólo funda la tesis según la cual nuestro saber de Dios se limita al conocimiento de su existencia, sino que también y de forma correlativa parece condenar cualquier eventual empresa de teología racional."

La declinación hobbesiana de todo proyecto de teología racional lleva forzosamente aparejada la imposibilidad de cualquier intento de teodicea, socavando así los dos conceptos axiales de la teodicea leibniciana a los que nos hemos referido. Hobbes ni siquiera estaba dispuesto a admitir el principio de identidad, que mantenía que dos verdades contradictorias no podían ser ciertas al mismo tiempo. Así lo manifiesta cuando declara que "Dios no quiso que los tres ángulos de un triángulo fueran iguales a dos rectos o que el mundo fuese creado en el tiempo porque conociese que esto no podía hacerse de otro modo", sino que, "porque quiso crear el mundo en el tiempo, por eso es así mejor que si lo hubiese creado desde la eternidad; y en la medida en que quiso que los tres ángulos de un triángulo fuesen iguales a dos rectos, es ahora cierto que es así, y no puede ser de otro modo" "I. Expresado en otros términos, cabe decir que la justicia de Dios no reside en las cosas mismas, sino en la voluntad que imprime sobre ellas.

Estas premisas se antojan del todo inconcebibles para Leibniz. El voluntarismo absoluto de Hobbes subvierte su principio de identidad. Si Dios pudiera haber hecho que la suma de los ángulos de un triángulo no equivaliera a la de dos ángulos rectos, se

8 ZARKA, Y. Ch. Filosofía y politica en la época moderna. Madrid: Escolar y Mayo Editores, 20o8, p. 84.

$9 \quad$ Ibidem, p. 85.

Io Ibidem.

II Ibidem, pp. 89-90. 


\section{REVISTA ANGELUS NOVUS}

pierde la idea de toda fundamentación lógica y matemática de las cosas, pudiendo ser dos enunciados contradictorios y verdaderos al mismo tiempo. De modo análogo, el principio de razón suficiente quedaba en suspensión, al ubicar en el fundamento de la cadena de causalidad un principio ajeno a la razón como era el Dios voluntarista. Contra ello, Leibniz va a acuñar un concepto completamente novedoso de voluntad divina que supere los efectos nocivos de la trascendencia absoluta hobbesiana: "Jamás la voluntad se ve arrastrada a obrar-afirma—si no es por la representación del bien, que prevalece sobre todas las representaciones contrarias" inclinación a hacer una cosa en proporción del bien en ella encerrado" ${ }^{13}$.

Desde esta perspectiva, la voluntad deviene una función que da existencia a la integridad ontológica que prevalece conceptualmente en las cosas mismas. Esto permite identificar la voluntad con la justicia, entendida como la actualización de las cosas efectuada por Dios de acuerdo con su necesidad conceptual. Así se corrobora cuando reprocha a Hobbes que "reduciendo la idea de justicia al mero poder, pervierte el sentido de justicia”:

La justicia en Dios, dice el señor Hobbes, (...) no es más que el poder que tiene, y que ejerce distribuyendo bendiciones y aflicciones. Esta definición me sorprende: lo que constituye la justicia no es el poder de distribuirlas, sino la voluntad de distribuirlas de manera racional, es decir, la bondad guiada por la sabiduría (...). La voluntad sin razón sería el azar de los epicúreos ${ }^{14}$.

Pese a estar convencido de haber salvado la autonomía y la libertad de la divinidad al tiempo que consolidaba el estatuto inapelable de las proposiciones de orden matemático, así como la regularidad y predictibilidad de los fenómenos físicos, la teodicea leibniciana tuvo aún que lidiar con algunas inconsecuencias ingénitas que sus críticos no dejaron de señalarle.

Y es que esa salvación de la autonomía del Dios creador pasaba por la conversión de la sustancia spinoziana en teodicea. Nuestro autor transita desde un necesitarismo metafísico y físico hacia un necesitarismo moral y personal. El problema a este sistema lo va a encontrar Leibniz no por el lado de la autonomía de la naturaleza, sino por el lado de la excepción. Esto es, si Dios hace el mundo existente en coherencia con un criterio de bondad, su intercesión por vías extraordinarias, el milagro, le llevaría a incurrir en la maldad. Esto no puede ocurrir en el necesitarismo spinoziano, pues el filósofo holandés postula la imposibilidad absoluta de lo distinto a lo existente (Res

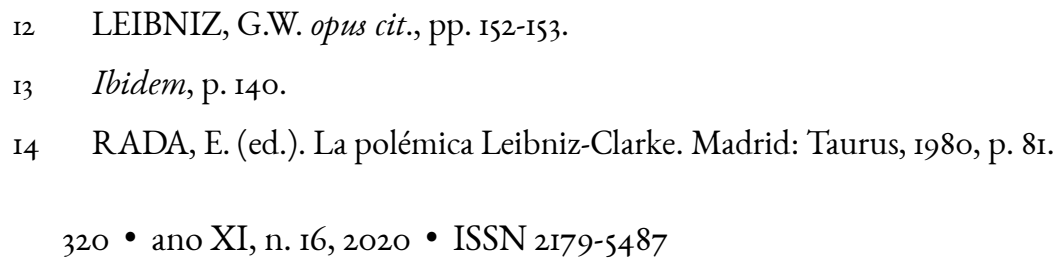


nullo alio modo, neque alio ordina a Deo produci potuerunt quam productae sunt's). Y es que la contingencia del milagro no sólo pone en aprietos a la persona divina al encauzarle por la senda de la decisión maliciosa, sino que es esencialmente incompatible con los dos elementos axiales del sistema spinoziano: por una parte, un milagro puede violentar las leyes lógico-matemáticas que gobiernan el mundo, y que el filósofo de Hannover reputa imprescriptibles; de otro lado, abre un orificio en la cadena de razones suficientes del cual la razón humana no puede dar cuenta. El milagro dinamita el sistema leibniciano desde toda óptica ${ }^{16}$.

Leibniz va a franquear estas cortapisas aduciendo que la percepción de los milagros como tales se deberían en todo caso a la finitud y limitaciones del aparato cognitivo humano. En estos términos se expresa sobre esta particular en la Theodicée:

(...) se dirá que, si todo está ordenado, Dios no puede hacer milagros. Pero es preciso tener en cuenta que los milagros que suceden en el mundo estaban ya incluidos y representados como posibles en este mismo mundo, considerado en estado de pura posibilidad; y Dios, que los ha hecho después, había ya decretado el hacerlos cuando escogió este mundo (...). Y como todo está ligado sabiamente en el mundo, es claro que Dios, previendo lo que libremente sucedería, ha arreglado el resto de las cosas de antemano, o (lo que es lo mismo) ha escogido este mundo posible donde todo estaba arreglado de esta manera ${ }^{17}$.

Leibniz era plenamente consciente de que este punto pasaba por ser la parte más débil y delicada de su sistema. Una postura abiertamente favorable a la posibilidad del milagro tal como la teología lo había entendido tradicionalmente no sólo contravendría de raíz todos los elementos quiciales de su argumentación, sino que le aproximaría a la órbita de la posición fideista y voluntarista. Desde esta óptica, la razón independiente se veía privada de su fundamento, ya fuese por la omnipotencia de Dios que presuponía Hobbes o por el hecho de que el azar gobernaba el mundo, tal como sostenían

"Las cosas no han podido ser producidas de ningún otro modo, ni en ningún otro orden, que como han sido producidas" (cit. en ISRAEL, J., 20I2, opus cit., p. 293).

16 No pretendemos dar a entender con esto que el vocablo "milagro" sea proscrito en la metafísica leibniciana, sino, más bien, tal como el propio Leibniz nos hace ver en Teodicea \$207 (p. 255), que su acepción tradicional en tanto que fenómeno que "no se puede explicar por la naturaleza de las cosas creadas" (a la manera de Hobbes) es del todo inasumible e inconcebible en los términos de su sistema. Aunque Leibniz no se refiere expresamente a que la excepción al orden de la razón aboca al mal, éste es un corolario lógico de su sistema fácilmente inferible. Pues, al identificar el Bien con el orden de la Creación, la virtualidad de la vulneración —a la cual Leibniz nunca se refiere, pues para él una manifestación de Dios segregada de la razón, contradiciendo los principios de no contradicción y de razón suficiente, se antojaba a todas luces inconcebible-de tal orden nos sitúa directamente en la órbita del mal. Si le elección moral libre de un Dios inteligente pasaba por ser la única alternativa para no sucumbir al necesitarismo spinozista, el precio a pagar era alto: identificar la excepción absoluta_insistimos, a la que Leibniz nunca se refiere-con el mal. 


\section{REVISTA ANGELUS NOVUS}

epicúreos y atomistas. Dicho en otras palabras, la ratio autónoma de la teodicea leibniciana se veía igualmente amenazada por lo suprarracional que por lo irracional. Por otro lado, una postura abiertamente en contra de la eventualidad del milagro le habría llevado a abrazar la necesidad que gobierna el orden de las verdades físicomatemáticas así como el de la naturaleza, asimilándolo con las posiciones spinozistas. La posición leibniciana está, huelga decirlo, más próxima del necesitarismo causalista spinoziano que del voluntarismo hobbesiano, si bien esto no es óbice para que nuestro autor tuviera que defender la libertad divina a la que vez su racionalidad predecible, todo ello al tiempo que negaba el milagro en su acepción tradicional de suspensión parcial de las leyes de la naturaleza.

En este empeño, Leibniz va a admitir, en congruencia con el principio de identidad, que resulta imposible a todas luces concebir un fenómeno contrario a la razón. Lo que los seres humanos experimentamos como milagros son fenómenos compatibles con la ratio divina, y en absoluto inconciliables con los principios de identidad y de no contradicción; el que nosotros los percibamos como tales obedecería al hecho de que estos fenómenos sobrepujan los parámetros de nuestros usos y costumbres, lo cual no conlleva en modo alguno que sean irracionales. A este respecto, Leibniz va a distinguir entre fenómenos contrarios a la razón y superiores a la razón:

(...) Porque lo que es contrario a la razón, lo es a las verdades absolutamente ciertas e indispensables; y lo que es superior a la razón es contrario sólo a lo que acostumbramos a experimentar y comprender (...). Una verdad es superior a la razón cuando nuestro espíritu (y aún todo espíritu creado) no la puede comprender; como sucede, a mi entender, con la Santa Trinidad; con los milagros reservados sólo a Dios, como, por ejemplo, la creación; con la elección del orden del universo que depende de la armonía universal y del conocimiento distinto de una infinidad de cosas a la vez. Pero una verdad no puede nunca ser contraria a la verdad, y lejos de ser incomprensible un dogma combatido y vencido por la razón, puede decirse que nada es más fácil de comprender ni más manifiesto que el absurdo que él encierra. Porque por razón no entendemos aquí las opiniones y discursos de los hombres, ni tampoco el hábito que han tomado de juzgar las cosas según el curso ordinario de la naturaleza, sino el encadenamiento inviolable entre las verdades ${ }^{18}$.

En esta misma línea se iba a expresar en el Discurso de metafísica ( $\$ 6$ y $\$ 7$ ) cuando aborda las modalidades bajo las cuales Dios actúa, concluyendo que ninguna de ellas resulta compatible con el concepto tradicional de milagro:

Las voluntades o acciones de Dios se dividen comúnmente en ordinarias o extraordinarias.

Pero es conveniente tener en cuenta que Dios no hace nada fuera del orden. Así, lo que 
pasa por extraordinario no lo es más que a la mirada de algún orden particular establecido entre las criaturas. Pues, en cuanto al orden universal, todo está de acuerdo con Él. Y tan cierto es eso, que no solamente no sucede en el mundo nada que sea absolutamente irregular, sino que ni siquiera podría fingirse nada semejante. (...) Mas cuando la regla es complicada, lo que no está conforme con ella pasa por irregular.

Puesto que nada puede hacerse que no esté dentro del orden, puede decirse que los milagros están también dentro de él, lo mismo que las operaciones naturales, que se llaman así porque están de acuerdo con ciertas máximas subalternas que nosotros llamamos la naturaleza de las cosas. Pues puede decirse que esta naturaleza no es más que una costumbre de Dios, de la que puede dispensarse a causa de una razón más poderosa que aquella que le ha movido a servirse de sus máximas. En cuanto a las voluntades generales o particulares, según se tome la cosa, puede decirse que Dios hace todo según su voluntad más general, que está conforme con el orden más perfecto que ha escogido; pero puede decirse también que hay voluntades particulares que son excepciones a las máximas subalternas dichas, pues la más general de las leyes de Dios, que regula toda la serie del universo, no tiene excepción ${ }^{19}$.

De esto se sigue un ingenioso corolario. Leibniz va a entender las excepciones a las leyes de la naturaleza a su vez como leyes. Lo que los seres humanos percibimos como suspensiones de las leyes de la naturaleza constitutivamente refractarias a toda fundamentación racional serían en realidad otras tantas leyes que colisionan con las que estamos habituados a presenciar. De ahí que, para evitar estos inconvenientes, este cortocircuito entre racionalidades concurrentes, Leibniz diga que Dios ha creado el mundo “más simple en hipótesis y más rico en fenómenos”, siendo tal ordenamiento el que propiciaría el menor conflicto entre las disposiciones de las distintas leyes generales $\mathrm{y}$, por ende, el que implica un menor número de excepciones a las leyes generales ${ }^{20}$.

La sabiduría divina que informa el orden de la creación, y que se sustancia en una ratio, es más perfecta que la humana. Con todo, en la mente de Leibniz ello no lleva aparejado, como ocurre con Hobbes, que existiera un clivaje insalvable entre la racionalidad humana y la divina ${ }^{21}$. El filósofo inglés estimaba que esta disimetría se

LEIBNIZ, G.W. Monadologia/Discurso de metafisica/Profesión de fe del filósofo. Barcelona: Ed. Orbis, 1983 , pp. 70-72.

BROWN, G. "Miracles in the Best of All Possible Worlds: Leibniz's Dilemma and Leibniz's Razor”. History of Philosophy Quarterly, Vol. 12, No. I (Jan., 1995), p. 23.

Los corolarios políticos que Hobbes infirió de este postulado teológico-epistemológico abren una vía de estudio muy fértil al ámbito de la filosofía política y filosofía del derecho que, por razones de espacio, aquí no podemos más que prefigurar. Si el derecho, al igual que el conocimiento, se funda sobre el prerrequisito de la omnipotencia divina, el orden resultante habrá de ser pensado como un orden de coerción, lo cual viene a disolver el nexo que los teólogos de la segunda escolástica trabaron entre el dominio divino y el orden natural de las cosas. El orden impuesto, escribiría el pensador inglés, retomando así los términos de una oposición clásica, no adopta la forma de un 
producía en la medida en que Dios se emancipaba de toda ratio en su proceder, en tanto que Leibniz va a proponer que ese desfase se debe a que Dios se pertrecha en su "hacer" de una ratio de orden superior cuyo desfase con la razón humana llevaría a los hombres a vislumbrar milagros allí donde en realidad existiría un proceder uniforme y razonado en total congruencia con los principios de identidad y de razón suficiente. Así, Leibniz pudo seguir refiriéndose a esta ratio de orden superior como sabiduría (esto es, como voluntad reglada), y no como una voluntad desbocada y segregada de toda ratio ${ }^{22}$. El misterio, fundamento del dogma religioso, queda de este modo circunscrito a los términos de una "razón de orden superior". Con esta adscripción de la categoría del milagro y del misterio a la imperfección y debilidad de la razón humana, Leibniz pudo salvaguardar su principio de identidad, que suponía que ningún fenómeno podía contradecir las reglas de la razón.

Acabamos de dar con el elemento que posiblemente represente la piedra angular del sistema de la teodicea leibniciana, y que, de paso, lo diferencia de la pura necesidad spinozista: la elección libre de un Dios moral. Esta moralidad connatural bosqueja un Dios personal que, al conformar su creación a la idea del bien, cuida de sus criaturas. Nada más lejos de la realidad, por cuanto la idea de Bien que maneja Leibniz dista mucho de identificarse con la erradicación de las aflicciones humanas. La idea del bien y el deber moral para Leibniz se cifra, antes bien, en una necesidad para con las demandas

consejo, cuya razón se derivaría de la cosa misma, sino de una ley que se impone por su sola voluntad y por la sola potencia de aquel que la ordena. Para un análisis más exhaustivo de estas nociones, cfr. RENOUX-ZAGAMÉ, M.F., Origines théologiques du concept moderne de propriété. Geneva: Librairie Droz, 1987, pp. 169-170. Desde este prisma, la disyunción entre consejo y ley se antoja homologable con la cesura que existe entre la voluntad divina sometida a criterios racionales e inteligibles leibniciana y la voluntad absoluta hobbesiana.

22 Hobbes derivaría de aquí que, al ser la razón humana esencialmente inadecuada al concepto de la divinidad, la sumisión incondicional a la autoridad de turno era el único modo de conjurar la perspectiva de la infinita disensión y, en último punto, de la "guerra de todos contra todos". De sigue de ello que las cosas no son buenas o malas en sí mismas, sino en función del fallo que la autoridad competente dicta sobre ellas. De manera contrastante con Leibniz, Hobbes asumirá que la razón humana no es universal ni alcanza verdades universales: la implementación del libre raciocinio sólo puede abocar a la eterna confrontación. De modo que allí donde Leibniz proyectará una Iglesia universal fundada sobre las reglas de la Razón universal, Hobbes prescribirá la sumisión de los ciudadanos a la autoridad de turno. A la vista de esto habría de entenderse su aseveración de que "Si hay nada en la Escritura de lo que pueda ser inferida la infalibilidad de la Iglesia romana, mucho menos se podrá asumir la infalibilidad de una Iglesia particular; y, menos aún, de un hombre particular" (cfr. a este respecto TRIOMPHE, M. "Hobbes, lecteur de la Bible dans le Léviathan”. In: La Bible dans le monde anglo-américain aux XVIIe et XVIIIe siècles. Société d'études anglo-américains des I7e et I8e siècles, pp. 60-6I, 1984. La autoridad pública ejerce un papel análogo al de Dios en la Creación y en el proceso de conocimiento: es su sola voluntad la que prescribe sobre el ser de las cosas, sin atenerse en su gobierno a ningún criterio previo a la decisión misma. Leibniz, en cambio, pudo creer en la transparencia de la autoridad política pública en tanto en cuanto prescribió para aquélla, como para Dios en su obrar, una supeditación a las normas de la razón. El gobierno, como Dios, actúa de acuerdo con las leyes universales de la razón, que son accesibles a todos los hombres en todas las épocas.

$324 \cdot$ ano XI, n. 16, $2020 \cdot$ ISSN 2179-5487 
de las proposiciones lógico-metafísicas. Esto lo percibió H. Blumenberg de manera perspicaz al apostillar que la filosofía de Leibniz no persigue tanto la preservación de la libertad divina cuanto los intereses de la competencia plena de la razón ${ }^{23}$ así como de su correlato físico, esto es, una naturaleza regular y uniforme no perturbada por la presencia de milagros.

El principio del orden en virtud del cual Dios somete en todo momento su hacer a exigencias metafísicas racionales (sean tales exigencias transparentes o no al intelecto humano) tendría por finalidad la "felicidad de las mentes". Es decir, el mundo, tal como existe, y se mire desde la óptica que se mire, produce la máxima gratificación a las mentes racionales. De ahí que, si aun en cierto momento tales o cuales acontecimientos nos pueden parecer irracionales, "cuanto más analizamos las cosas, más satisfacen éstas nuestro intelecto". Y el placer y la felicidad de los seres inteligentes consistiría en "la percepción de la belleza, el orden y la perfección”. El mundo existente es el "mejor", no porque sea el que más exima a los seres humanos de sus sufrimientos cotidianos, sino por el hecho de que es racional y metafísicamente óptimo, enteramente compatible y aprehensible desde la matemática y la geometría. No es otra, pues, la noción de "felicidad" que se desprende de esta teodicea en la que el Bien se identifica con las exigencias de la razón y la autonomía de los fenómenos físicos. Del mismo modo que "teodicea" no significa para Leibniz la mejor de las perspectivas para los humanos en el mundo, la "felicidad" concomitante a esta teodicea no puede tampoco identificarse con la extinción de los males del mundo y del sufrimiento de los hombres.

Visto desde este prisma, se torna admisible postular que, de la mano de su concepto de deber moral presidiendo las acciones de Dios, Leibniz no buscaba tanto personalizar la máquina independiente en que la física y metafísica del siglo XVII habían convertido la obra de Dios cuanto revestir dicha máquina de un cariz moral. Esto último se constata cuando se confronta la explicación que ofrece del mal. Si el mal y el crimen pululan por doquiera en el mundo, ¿cómo contemporizar este hecho con la premisa de que el género humano habita el mejor de los mundos posibles? Leibniz responderá que aquellos autores que, como P. Bayle, asumen que Dios, dada su omnipotencia, pudo o puede erradicar el pecado y el correlativo mal del mundo, erran al confrontar la problemática desde la perspectiva de la pura felicidad humana. Y es que, a su entender, el mundo sería el mejor de los posibles no de acuerdo con la cantidad de felicidad humana en él existente, sino en función de la sabiduría que Dios plasma en el mismo; una sabiduría que comprende muchas otras variables más allá de la neta felicidad de los hombres.

BLUMENBERG, H. La legitimación de la Edad Moderna. Valencia: Pre-Textos, 2008, pp. 84-85. 


\section{REVISTA ANGELUS NOVUS}

Algún adversario dice que el mundo ha podido existir sin pecado y sin padecimientos; pero niego que entonces hubiera sido el mejor. Porque es preciso tener entendido que todo está ligado en cada uno de los mundos posibles; que el Universo, cualquiera que sea, es todo de una pieza, como un Océano; el menor movimiento hace sentir su eco a todas las distancias. (...) Dios lo ha ordenado todo de antemano de una vez para siempre, habiendo previsto los ruegos $\mathrm{u}$ oraciones, las buenas y las malas acciones, y todo lo demás; y cada cosa ha contribuido idealmente antes de su existencia a la resolución que ha tomado sobre la existencia de todas. Así que nada puede mudarse en el Universo (como no se puede en un número). (...) Por lo tanto, si llegara a faltar el menor mal que sucede en el mundo, ya no sería este mundo, que, tomándolo todo en cuenta el Creador que lo ha escogido, ha encontrado que era el mejor ${ }^{24}$.

La explicación metafísica de este punto se cifra en que la mente divina se compondría de una serie de unidades conceptuales elementales respecto a las cuales Dios, conducido por su infinita bondad y sabiduría, estaría obligado a dar cuenta en la creación. La plasmación fiel de este orden de unidades sustanciales (que Leibniz va a denominar mónadas) en la esfera del mundo creado sería lo que llevaría aparejado el mal. Dios tendría el poder para subsanar estos desarreglos mediante intervenciones puntuales, pero, caso de hacerlo, socavaría el equilibrio racional y conceptual que su mente le dicta, dando al traste con el encadenamiento de verdades físicas y metafísicas. La observancia por parte de Dios de estas verdades conceptuales en el momento de la creación lo va a llamar Leibniz voluntad antecedente divina. Esta voluntad es puramente apriorística y conceptual, precede a la creación y "considera cada bien aparte en tanto que es bien"2s. Por otro lado, al orden de la realidad creada donde surge el conflicto entre las ideas de la voluntad antecedente llevadas a la existencia recibe el nombre de voluntad consecuencial, la cual se regiría por la máxima de que "jamás deja de hacerse lo que se quiere cuando se puede". ${ }^{26}$ Esta última resultaría del "conflicto entre todas las voluntades antecedentes ${ }^{27}$. Se desprende de aquí que el sufrimiento es un resultado de la plasmación fidedigna que Dios efectúa de las verdades antecedentes en la esfera mundana. La consumación de la integridad conceptual a priori de las sustancias redunda en mayor sufrimiento para los hombres. La aflicción no es, pues, sino un corolario del prurito metafísico de Dios en su obrar. Dirá así Leibniz que la voluntad consecuente de Dios que tiene por objeto el pecado no es más que permisiva ${ }^{28}$, en la

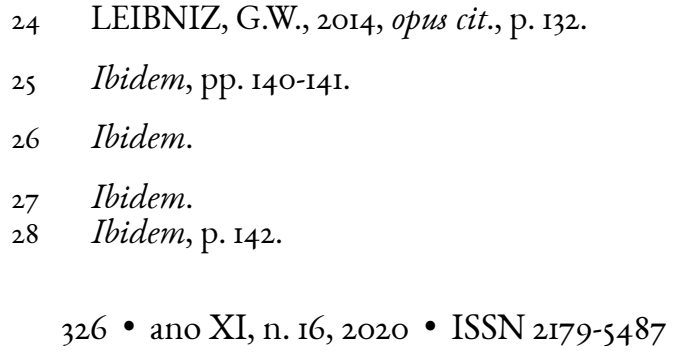


medida en que hace las veces de sine qua non para un bien mayor, a saber, la realización de las verdades sustanciales que anidan en su mente.

El modo de razonar de Leibniz opera en el sentido de una fundamentación extrínseca y a posteriori del sujeto que presume a éste toda la suma de predicados que deben iluminar su actividad moral. Este proceder lo acabamos de ver aplicado al deber moral divino, donde la bondad de Dios se infiere directamente del orden lógico, matemático y geométrico, de un lado, y del orden de la causación física del mundo de otro. Leibniz pondrá esto de manifiesto de manera taxativa al afirmar que "en toda proposición afirmativa, verdadera, necesaria o contingente, universal o singular, la noción del predicado está comprendida en la del sujeto: predicatum inest subjecto" ${ }^{29}$. El sujeto leibniciano no es más que la salida natural que encontró a la necesidad que planteaba su sistema de vertebrarse en una razón suficiente que diera cuenta de toda la diversidad metafísica y física. Sirva de ejemplo la mónada que reside en la mente divina y que tiene su traslación en el mundo real, dándose una identificación cabal entre la mónada que habita la mente divina y la mónada realizada. La única excepción planteada a la regla puede venir dada por Dios, cuya omnipotencia rebasa toda atribución predicativa, tornando imposible una identificación absoluta entre los predicados y el sujeto. Empero, declarará Leibniz que Dios actúa guiado por un "bien moral”: quizá los predicados no den cuenta de todo el sujeto divino, pero sí de su radio de acción moral; de hecho, no es sino tal moralidad, como hemos tenido ocasión de ver, la que fundaría y haría posible la teodicea.

Spinoza razonaba de un modo homólogo cuando trabó la relación existente entre sus dos principios nucleares: la Natura Naturans y la Natura naturata. La primera noción designaba a Dios en tanto que agente motor. El segundo término hacía alusión al producto de la realización total de los atributos divinos. La ilación de estos términos nos aboca casi a la tautología. Pues iqué necesidad tendría la naturaleza de ser naturalizada? Si atendemos a la definición ofrecida por el propio Spinoza, la relación entre ambas nociones no divergiría esencialmente de aquella que Leibniz establece entre sujeto y predicado, o, en la teodicea, entre el Dios creador y el mundo creado. La Natura Naturans designa lo que existe independientemente en sí mismo y existe y se concibe a través de sí mismo, es decir, "Dios en tanto es considerado una causa libre”. Por Natura naturata se entiende, en cambio, todo lo que se sigue de la necesidad de la naturaleza divina, o de algunos de los atributos de Dios..." ${ }^{\circ}$. La única diferencia, bien

29 FERNÁNDEZ-GARCÍA, Mạ., 2000, opus cit., pp. 136-I37.

3o MELAMED, Y. "Why Spinoza is not an Eleatic Monist (Or Why Diversity Exists)". In: GOFF, P. (ed.). Spinoza on Monism. London: Palgrave Macmillan, 20I2, p. 208. 


\section{REVISTA ANGELUS NOVUS}

que sustancial, es que Spinoza establece una relación de necesidad entre ambas nociones que deriva en una identidad del todo indiferenciada ${ }^{31}$. Leibniz, en cambio, pudo mantener la dualidad de las sustancias por mor de la introducción del "deber moral”; su identidad entre sujeto y predicado no deriva tanto una necesidad absoluta cuanto de un imperativo moral. El deber moral se convierte, pues, junto con los ya referidos principios de identidad y de razón suficiente, en la clave de bóveda de todo el entramado leibnicano, en tanto que válvula de escape al necesitarismo físico-metafísico. Por lo tanto, y a tenor de todo lo sobreexpuesto, estamos en condiciones de aseverar que, lejos de salvar la libertad divina de las constricciones de la necesidad metafísica, Leibniz identificó esa necesidad con el Bien. Las verdades de la razón y la filosofía debían abrirse paso, no a través de la necesidad, sino de la antigua moralidad cristiana. La filosofía no expulsaba a la teología revelada de todos sus dominios hegemónicos arguyendo la sola Verdad, sino el Bien que anida en aquélla. La trascendencia a las verdades de la filosofía (es decir, el terreno de la antigua teología revelada) escondía ahora todo tipo de sombras y amenazas. Si en el sistema panteísta de Spinoza la excepción a la razón natural y a las verdades de la filosofía constituyen el verdadero ateísmo ${ }^{32}$ (toda vez que Dios es efectivamente la Naturaleza y su orden de verdades), en Leibniz la excepción y la trascendencia respecto a las verdades de la razón y la filosofía apuntan directamente al Mal, en tanto en cuanto tales verdades están fundadas sobre el bien supremo.

\section{Economía y teodicea en la obra de Malebranche}

Como Leibniz, Malebranche concibió un sistema filosófico en el que se trataba de contemporizar la libertad de Dios en la creación y su intercesión en los asuntos mundanos (Providencia) con la regularidad imperturbable de las leyes de la naturaleza y la vigencia irrecusable de las verdades de la física y de la matemática. La homología

3I Cfr. este extracto de la Ética como prueba de la identidad spinozista entre Natura naturans y Natura naturata: “(...) cada cosa natural tiene por naturaleza tanto derecho como poder para existir y actuar. Ya que el poder por el que existe y actúa cada cosa natural es el mismo poder de Dios... (...). Así pues, por derecho natural entiendo las mismas leyes o reglas de la naturaleza conforme a las cuales se hacen todas las cosas, es decir, el mismo poder de la naturaleza” (en BALIBAR, E. Spinoza y la politica. Buenos Aires: Prometeo Libros, 1996, pp. 51-52).

32 A propósito del desbanque de la teología por parte de la filosofía como ciencia preeminente de las verdades religiosas, Spinoza se expresará en los siguientes términos en el Tratado teológico-político (SPINOZA, B. Tratado teológico-político. Pamplona: Laetoli, 2014, p. 282): “aunque la Religión tal como los Apóstoles, en cuanto se limitaban a narrar la historia de Cristo, no cae bajo el dominio de la Razón, cualquiera puede, sin embargo, alcanzar por la luz natural una síntesis de la misma, ya que consiste esencialmente, como toda la doctrina de Cristo, en enseñanzas morales.”

$328 \cdot$ ano XI, n. 16, $2020 \cdot$ ISSN 2179-5487 
estructural entre ambas teodiceas ha sido recogida extensamente y desde múltiples perspectivas, acumulando así la temática una profusa bibliografía. Más allá de dicha pluralidad de enfoques, todos los autores convienen, empero, en que, a pesar de las obvias diferencias que existen entre sus respectivas teodiceas (reseñada por los mismos autores en su correspondencia personal), el empeño por poner de manifiesto estas diferencias estriba precisamente en la similitud de sus empresas filosóficas ${ }^{33}$.

Malebranche afirma que Dios ajusta su actividad en la creación a un criterio de economicidad. De modo que, al crear el mundo, Dios no toma sólo en consideración el resultado final del acto (es decir, la bondad y perfección de la creación per se), sino la “simplicidad de los medios” utilizados para ello. La razón de esto habría de buscarse en el hecho de que emplear los medios más simples, uniformes y universales trasuntaría en la misma medida a la divinidad de lo que la perfección de la creación lo hace ${ }^{34}$. En resumidas cuentas, valga decir que, a juicio del filósofo y teólogo francés, Dios ha creado, entre las infinitas posibilidades que se dan cabida en su mente, aquel mundo que mejor concilia la perfección del diseño (ouvrage) con la uniformidad, simpleza y generalidad de los medios empleados en su producción y conservación (desseins). Luego, el rasgo distintivo de la divinidad es su economía, el actuar por "voliciones generales" (volontés générales) y por los "medios más simples" (les voies les plus simples), todo ello en aras de "maximizar su propia gloria" 35 , es decir, a trasuntar en el orden de la creación una realidad lo más cercana posible a su propio ser, tal como nos consigna en el tercer Eclaircissement del Traité: "El ser infinitamente perfecto se ama necesariamente. Él no puede querer nada que por su propia voluntad, esto es, por el amor que se debe a sí mismo. Él no puede actuar que para sí mismo.” ${ }_{6}$

Lógicamente, Malebranche asume-a diferencia de Spinoza, a quien (huelga decirlo) se opone diametralmente-el carácter creado del mundo y, extensivamente, la libertad que preside la acción creadora de Dios. En las Entretiens sur la métaphysique $(\mathrm{X}, \mathrm{I7})^{37}$ el personaje de Theodore, representante de la filosofía de Malebranche, nos expone los criterios bajo los cuales Dios habría operado en el acto originario de la

33 NADLER, S. "Choosing a Theodicy: The Leibniz-Malebranche-Arnauld Connection". In: Journal of the History of Ideas, vol. 55, n. 4, p. 574, 1994.

34 Ibidem, p. 576.

35 BLACK, A. "Malebranche's Theodicy”. In: Journal of the History of Philosophy, vol. 35, n. I, p. 28, 1997.

36 MALEBRANCHE. Traité de la nature et de la grace (vol. 5). Paris. J. Vrin, 1976, p. 179. En Malebranche, N. Oeuvres complètes. París: J. Vrin, 1978.

37 MALEBRANCHE. Entretiens sur la métaphysique et sur la religion/Entretiens sur la mort (vols. XII-XIII). Paris. J. Vrin, 1984, pp. 247-249. En Malebranche, N. Oewures complètes. París: J. Vrin, 1978. 


\section{REVISTA ANGELUS NOVUS}

Creación: "esta primera impresión del movimiento sabiamente distribuida bastaba para formar de una sola vez los animales y los plantas, que son las obras más excelentes que Dios haya hecho de la materia”. De esto se sigue que el universo fue creado y organizado al mismo tiempo y en la misma operación: todo su desenvolvimiento ulterior estaría previsto por su autor desde su primer minuto de vida. ${ }^{3}$ Por otra parte, en este plan histórico Malebranche incluye una suerte de historia de la salvación por la cual el fin que Dios habría proyectado para su obra desde un principio, implícitamente en su mismo concepto, sería la reconciliación del género humano con su creador por medio de la encarnación de Cristo y el establecimiento de su Iglesia. Es según esta telos final desde el que habría que juzgar los males puntuales que pueblan el mundo y afligen a los seres humanos que lo habitan. Se imponía aquí una disyuntiva homóloga a la del Dios de Leibniz cuando la puesta en efecto de su voluntad antecedente acarreaba ciertos desarreglos y males incidentales en el plano de su voluntad consecuencial. El plan se debe juzgar, en definitiva, observado en su conjunto y a la vista de su fin último. Si Leibniz advertía de que mientras más observamos la creación, más conscientes nos haremos de su perfección y belleza, Malebranche agregara a esta presunción racionalista la promesa de la salvación y de la reconciliación de la humanidad pecadora y caída con su creador.

Ahora bien, esta delectación en el plan de Dios para el mundo se complementa y es inescindible de la hechura matemática y metafísica de dicho mundo, dando tales atributos razón del carácter sabio y sumamente inteligente del ser divino. Apelando al Génesis, Malebranche observa que después de la creación, Dios descansa. Pero este "descanso" de la divinidad no se puede asimilar con la ociosidad a la que se entregan los hombres, puesto que el dogma de la Providencia exige que Dios lo haga todo y en todas las cosas. Este descanso tendría que ser interpretado como el punto de inflexión por el cual Dios deja de actuar a través de voluntades particulares como la que supuso la creación de la nada para pasar a operar según voluntades generales. Así nos lo hace ver en las Entretiens 39 $^{9}$ IV, Io) cuando asegura que "no es que él [Dios] no haga nada; él reposa, en efecto, pero porque no actúa sino de un modo que representa admirablemente el carácter de sus atributos”. La acción por la que Dios conserva las criaturas "es la misma que la de su creación, y su conservación continua no significa otra cosa que su creación continua, siendo el efecto de una voluntad que subsiste siempre la misma”. De ahí que se pueda decir con propiedad que "el instante de la creación no es algo pasado" (Entretiens VII, 7$)^{40}$.

38 GOUHIER, H. La philosophie de Malebranche et son expérience religieuse. Paris: J. Vrin, 1948, pp. 37-38.

39 MALEBRANCHE, Entretiens sur la métaphysique et sur la religion..., p. 95.

$40 \quad$ Ibidem, pp. I56-I57.

$330 \cdot$ ano XI, n. 16, 2020 • ISSN 2179-5487 
He aquí el sentido particular que reviste la noción de "voluntad general" en la teodicea de Malebranche. Este carácter regular y predecible de la naturaleza, confluyente con los atributos de la propia divinidad, nos es mostrado a través de la inquisición metafísica del mundo y de la realidad. Allí donde un entendimiento tosco o grosero podría observar milagros, la razón nos mostrará que en todo momento rige en el universo y en el mundo físico un orden y una regularidad compatibles con las verdades matemáticas y geométricas. El carácter racional del cosmos y la creación se abren, de este modo, a una suerte de goce intelectual que es al mismo tiempo contemplativo, pues observar y apreciar el carácter inteligible de la creación se convierte en una estimación de la propia divinidad creadora. En línea con esto afirmaría Malebranche: "no admiro tanto los árboles cubiertos de frutos y las flores como su crecimiento maravilloso de acuerdo con las leyes naturales.” ${ }^{4}$

Del mismo modo que Dios alberga un plan general para la historia humana, siendo necesario entender todos los males que trufan su decurso en vista de este fin último, dispone igualmente un plan general para el desenvolvimiento del mundo físico. Lo que se llama Naturaleza sería, pues, en rigor, "las leyes generales que Dios ha establecido para construir o conservar su Obra por las vías más simples y siempre de acuerdo con una acción uniforme, constante, perfectamente digna de una sabiduría infinita y de una causa universal" ${ }^{42}$. En este extremo, el sistema de Malebranche también se acompasa cabalmente con el de Leibniz: la simplicidad de las leyes y el hecho de que mediante unas pocas leyes generales se pueda dar cuenta de toda la diversidad de la creación bajo términos y parámetros racionales darían fe a su vez del carácter sabio y racional del creador: "Hay modos de obrar simples, fecundos, generales, uniformes y constantes; y los hay también compuestos, estériles, particulares, desordenados e inconstantes. Los primeros son preferibles a los segundos; porque marcan la sabiduría, bondad, constancia e inmutabilidad de aquel que los emplea: los otros marcan falta de inteligencia, malignidad, inconstancia y ligereza de espíritu”.

¿Bajo qué condiciones va a admitir, entonces, Malebranche la virtualidad del milagro? El partido jansenista, adscrito a una concepción rigurosamente agustiniana del pecado y de la gracia, acusó a Malebranche invocando una ecuación tan simple como "Dios gobierna mediante voluntades generales, ergo no actúa jamás según en la forma de voluntades particulares; ergo, no existe el milagro". Huelga decir que esta fórmula supone una simplificación supina del pensamiento del autor. Para ponderar el peso real

4I Cit. en GOUHIER, opus cit., pp. 39-40.

42 Cit. en RUTHERFORD, D. "Malebranche Theodicy", in Nadler, S (ed.). The Cambridge companion to Malebranche: Cambridge University Press, 200o, p. 173. 


\section{REVISTA ANGELUS NOVUS}

del concepto del milagro hemos de atender al Orden que Dios establece en la Creación, en el cual se encuentra comprendido y previsto todo el devenir ulterior. No cabe en Malebranche acontecimiento alguno que contradiga este plan, del mismo modo que en Leibniz se antojaba del todo inconcebible un acontecimiento que contradijera de plano las leyes de la razón. Ahora bien, a partir de aquí Malebranche entiende que si con vistas a llevar a buen término el plan previsto en ese Orden, Dios tiene que deponer las leyes generales, interviniendo en la historia y haciendo un milagro, lo hará. Con todo no es tal el modus operandi propio de Dios, que lleva a efecto sus propósitos haciendo uso del mínimo de leyes posibles. En el Traité de la nature et de la grace (I, 20) se expresa elocuente y concluyentemente sobre este punto:

Dios no tiene más que dos leyes: el orden que es su ley inviolable, su ley natural, su Verbo, o su Sabiduría, que él ama invenciblemente; y los decretos divinos, leyes arbitrarias, de las cuales no se sustrae jamás, a menos que el orden así se lo exija; porque va contra el orden mismo que un Ser sabio e inmutable cambie de conducta sin razón alguna ${ }^{43}$.

Así pues, y siendo rigurosos con los textos de Malebranche, podríamos establecer la siguiente jerarquía en los modos de obrar adoptados por la divinidad: I) Dios actúa en la mayoría de los casos a través de voluntades generales; 2) Dios actúa a veces por medio de voluntades particulares; 3 ) Dios actúa siempre siguiendo el Orden ${ }^{44}$.

De esta clasificación se seguiría que, como ocurre en el entramado leibniziano, la perspectiva de un milagro en un sentido voluntarista, como fenómeno completamente desprendido de una razón, es radicalmente desechada, pues ello resultaría a su sentir esencialmente incompatible con la naturaleza divina, tal como pone se pone de relieve en las Entretiens (IV, Io) cuando propugna que "Dios no hace nunca milagros, no actúa nunca contra sus propias leyes, a no ser que el Orden lo exija o lo permita." ${ }^{4}$ Malebranche se va acercando de esto modo cada vez más a lo que podríamos denominar postulación racional del misterio, es decir, admitir un orden de razón incluso en aquellos fenómenos donde ésta parece quedar en suspenso. A su juicio, aquellos avatares que a los seres humanos les parecen incomprensibles y de los que su mente finita no puede dar razón formarían parte también del Orden inmutable que Dios se reserva para el mundo, tal como observa en el último Eclaircissement del Traité: "Estoy convencido de que la mayor parte de los efectos milagrosos de la antigua ley tenían lugar de acuerdo con algunas leyes generales, porque la causa general no debe en modo alguno ejecutar 
sus designios por voluntades particulares.” ${ }_{46}$ Tal sería el caso de los ángeles, cuya habitual intercesión en la historia bíblica no supondría una vulneración continua de las leyes naturales, sino que actuarían de acuerdo con leyes generales establecidas por Dios que, sin embargo, escapan al entendimiento humano. Malebranche coincide aquí plenamente con el sentir de Leibniz, quien se hace eco de esta argumentación en Teodicea \$249:

En cuanto a los milagros, no son todos quizás de la misma clase; hay muchos que procura Dios por el ministerio de algunas sustancias invisibles, como los ángeles, y así lo dice también el reverendo padre Malebranche; y estos ángeles o estas sustancias obran según las leyes ordinarias de la naturaleza, estando unidos a cuerpos más sutiles y más vigorosos que los que nosotros podemos manejar. Estos milagros solo lo son comparativamente y con relación a nosotros; a la manera que nuestras obras las tendrían por milagrosas los animales, si fuesen capaz de hacer sobre este punto observaciones ${ }^{47}$.

El hecho de que todas las acciones de los seres que habitan el mundo se conformen a las leyes generales previamente dispuestas por Dios nos da la clave para comprender sus teorías del "ocasionalismo" y de la visión en Dios. La teoría ocasionalista postula que Dios toma parte en la creación continua del mundo a través de la disposición de las leyes generales en coherencia con, y gracias a, las cuales los seres que lo habitan desarrollan sus acciones. Por ejemplo, cuando un individuo levanta un brazo lo haría en virtud de la ley general por la cual Dios dispone la unión del alma y el cuerpo. Lo mismo cabría decir, en la historia bíblica, respecto al arcángel Miguel o al propio Cristo, quienes actúan y llevan a cabo su labor en función del plan y el orden antecedentemente previstos por Dios. La visión en Dios, por su parte, remite el cúmulo de ideas que posibilitan el ejercicio del conocimiento-que Descartes suponía como innatas a la conciencia-a ocasiones de acuerdo con las leyes generales establecidas por Dios. El ejercicio del conocimiento pasa así a reglamentarse como una intervención de Dios de acuerdo con leyes y principios justos, razonables y uniformes. Si las tesis de Descartes tendían a apuntalar la autosuficiencia de la conciencia y el pensamiento, en Malebranche la independencia del pensamiento no puede ser escindida de su vínculo con Dios. Así pues, en las Entretiens (I, Io) ${ }^{48}$ objetará al padre del racionalismo que, si efectivamente "nuestras ideas son eternas, inmutables y necesarias, se sigue claramente que ellas deben encontrarse en una naturaleza inmutable, como es la de Dios". De este modo, el tipo de conocimiento idiosincrático de la filosofía moderna, nucleado sobre

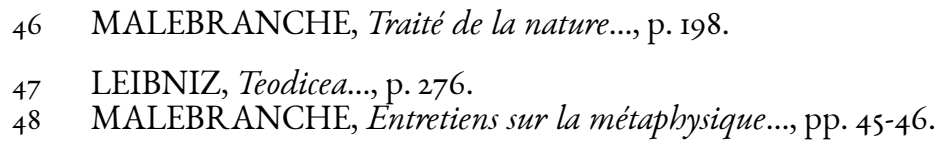




\section{REVISTA ANGELUS NOVUS}

ideas evidentes y claras, declara su total dependencia del Dios cristiano; pero, en la misma operación, dicho Dios cristiano abandona los derroteros de la revelación y de la gracia para convertir la certeza y la claridad en su modo predilecto de manifestarse, priorizando la ley frente al prodigio, la regla sobre el misterio. Ahora bien, ello no significa que, en el ejercicio intelectivo, los seres humanos tengan una aprehensión absoluta de Dios en las ideas que éste les dispone, sino que tal aprehensión de la sustancia divina sería relativa a su condición de seres creados y, consecuentemente, finitos. En Recherche de la verité (III, 2) nos aclara que a los seres humanos se le abren dos vías para el conocimiento de los objetos: se pueden conocer las cosas, bien por sus ideas, o bien en sí mismas. La primera es el modo de conocer propio del hombre; el segundo, sólo a Dios concierne ${ }^{49}$. En definitiva, Malebranche concluye que el alma no puede recibir las ideas a través de las que construye el conocimiento sin una influencia misteriosa de Dios, el cual no se mostraría tanto en sí mismo (objetivamente) cuanto como imagen en nuestra conciencia (efectivamente) ${ }^{\varsigma}$.

La posición de Leibniz respecto al ocasionalismo y a la visión en Dios se muestra mudable y vacilante. Si bien en una carta fechada el 22 de junio de 1679 dice "aprobar maravillosamente" esos dos principios, a saber, que vemos todas las cosas en Dios y que los cuerpos no actúan propiamente sobre nosotros ${ }^{51}$, en la Teodicea (\$206 y \$207) $)^{\text {52 }}$ observa que, a su juicio, "Dios jamás tiene voluntades particulares en la forma en que lo entiende Malebranche, es decir, particulares primitivas”. Pese a lo que pueda parecer, la discrepancia no es esencial: se dirige al comentario que Malebranche efectúa en el Traité $(\mathrm{I}, 2 \mathrm{O})$ en el que asegura que, de precisarlo el orden, Dios puede actuar de acuerdo con voluntades particulares. A esto le reprochará Leibniz más adelante, en esta misma carta, que el hecho de que el Orden eterno exija en cierto momento la intervención de Dios por medio de una voluntad particular resulta inconsecuente con el orden mismo, pues dicho orden prescribe que Dios actúa, de acuerdo con su propio concepto, siempre por los medios más simples a su disposición.

Este rigor económico implícito al concepto mismo de la divinidad explicaría la profusión de males que acaecen en el mundo. En efecto, Dios es omnipotente para, actuando mediante milagros (volontés particulières), erradicar todos los males que acongojan la existencia de las criaturas. Sin embargo, el proceder así sería un denuesto

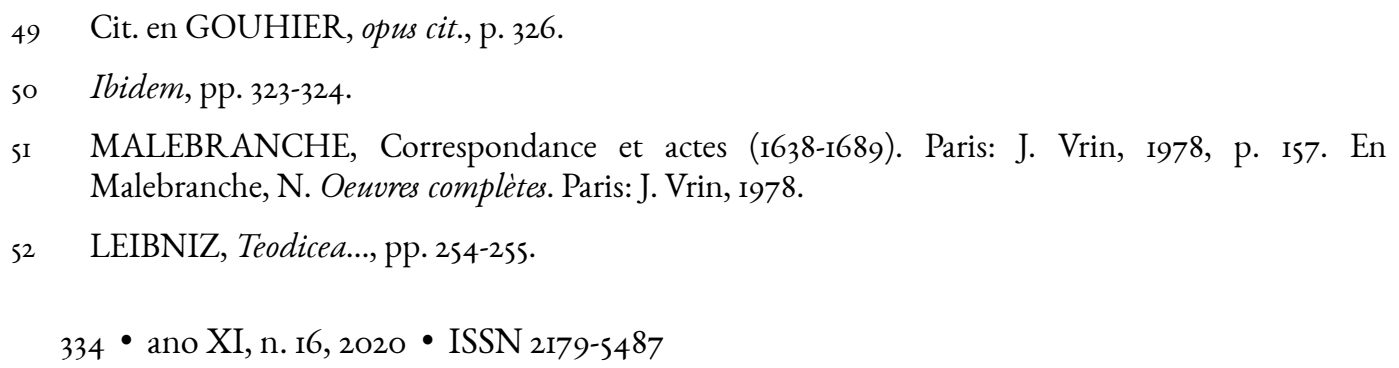


para el concepto de economía que ha de presidir sus obras. Vemos que la reflexión malebranchiana guarda ostensibles concomitancias con el sistema de Leibniz en este punto. El filósofo alemán juzgaba asimismo que, de actuar Dios por vías extraordinarias, vulneraría las leyes de simplicidad que su sabiduría le prescribe, y, por ende, sería infiel a sí mismo. Sin embargo, del mismo modo que Leibniz apelaba a buscar la racionalidad y la geometría que de seguro han de anidar en todo desorden, Malebranche justificaba, además de en razón de la simplicidad de los medios divinos, los males puntuales en vista del gran plan que Dios albergaba para el mundo: la salvación de todos los seres humanos bajo la Iglesia establecido por Cristo. El ejemplo de la revelación de Cristo para traer la salvación a todos los hombres le sirve a Malebranche para explicar su doctrina de las ocasiones generales:

Es Dios quien da al alma de Jesucristo todos los pensamientos y todos los movimientos de que ella precisa para la formación de su cuerpo místico. De manera que, si por un lado las voluntades de Jesucristo determinan, como causas ocasionales o naturales, la eficacia de la voluntad general de Dios, de otra parte, es Dios mismo quien determina las diversas voluntades de Jesucristo. Esto nos enseña que, en definitiva, las voluntades de Jesucristo son siempre conformes a aquellas del Padres3.

D. Rutherford hace notar que la clave de bóveda del sistema de Malebranche consiste en resaltar la identidad de Cristo como la verdadera encarnación de la sabiduría: la única alma cuyas voliciones se acomodarían perfectamente al orden eterno ${ }^{54}$. El amor a Dios se identifica y queda absorbido en el amor que los seres humanos deben a la racionalidad y la simpleza que su obra trasunta: "Te haces más admirable-dice Malebranche al creador- cuando cubres la tierra de frutos y de flores por las leyes generales de la naturaleza que cuando, por medio de voluntades particulares, precipitas el fuego desde los cielos para reducir a cenizas a los pecadores y sus ciudades"ss. No otro era el parecer de Leibniz cuando, en las Discusiones metafísicas $\$_{4}$, declara que "el conocimiento general de esta gran verdad, que Dios obra siempre de la manera más perfecta y de la forma más deseable, es, a mi entender, el fundamento del amor que debemos a Dios sobre todas las cosas, pues quien ama busca su satisfacción en la felicidad o perfección del objeto amado y de sus acciones." ${ }_{56}^{6}$ En ambos sistemas filosóficos, el amor incondicionado que en el cristianismo se debe a Dios en tanto que algo absolutamente desconocido y de lo que se depende se trueca en una permuta en

53 MALEBRANCHE, Traité de la nature..., p. 162.

54 RUTHERFORD, D. opus cit., pp. I83-184.

55 Cit. en GOUHIER, H., opus cit., p. 68.

56 LEIBNIZ, Monadologia/Discurso de metafisica/Profesión de fe del filósofo..., p. 68. 


\section{REVISTA ANGELUS NOVUS}

virtud de la cual la racionalidad y la predictibilidad del creador se antoja la condición de posibilidad de que el creyente le profese amor. No se ama a un Dios que resulta ser perfecto, sino que el amor que se debe a la perfección se concreta en amor hacia un ser que obra según aquélla.

Una pauta homologable aplicaría en lo atinente a la distribución de la gracia. Si la teología revelada, con los infinitos matices dados por la pluralidad de iglesias, confesiones y credos sujetos a circunstancias y vicisitudes históricas singulares que comprende este término, interpretaba la gracia como una dádiva divina que revestía un carácter esencialmente arbitrario, Malebranche va a subsumir su distribución al mismo criterio de economicidad que hizo valer en el orden de la creación y de las leyes físicas de la naturaleza. Un paquete de unas pocas leyes predetermina la distribución de gracia entre los hombres. Tal mecanismo de distribución de la gracia discurre paralelo a las condiciones bajo las cuales Leibniz admitía la existencia del milagro, a saber, como fenómenos que la ratio divina ha previsto que acontezcan pero que, empero, escapan al raciocinio humano:

Dios ama a los hombres. Quiere que todos sean salvados, quiere santificarlos a todos, quiere hacer una bella Obra, quiere hacer su Iglesia lo más amplia posible. Pero Dios estima en un grado infinitamente mayor su propia sabiduría: porque él la ama invenciblemente, la ama de modo natural y necesario. No puede sustraerse de actuar del modo más sabio y más digno que le conviene, de seguir aquella conducta que representa los máximos caracteres de sus atributos. Ahora bien, actuando Dios por los medios más simples y más dignos de su sabiduría, su obra no puede ser ni más bella ni más amplia de lo que efectivamente es5.

Constatamos, pues, que el reino de la gracia se regula por las mismas leyes simples que rigen para el orden de la naturaleza. Asimismo, tanto en uno como en otro las pretendidas imperfecciones y males deben ser calibradas en función del plan y el orden mayor que Dios alberga. El orden de la naturaleza y de la gracia son igualmente expresivos de la sabiduría divina. Dios bien podría haber evitado los males del mundo físico disponiendo una plétora de voluntades particulares, mas con ello habría contravenido su infinita sabiduría. Dios también podría haber repartido la gracia individualmente entre los hombres que la merecen y que sin embargo se ven privados de ella, o podría haber evitado el pecado original; sin embargo, se ha de tener presente que permite todo esto en orden a una reconciliación final con la venida de Cristo y el establecimiento de la Iglesia. 
El elemento clave que queremos aquí considerar-a la luz del cual se despliega una línea comparativa con Leibniz-es si en la teodicea de Malebranche el economicismo y la simplicidad que presiden los modos de acción de la divinidad también absorben la noción del Bien y de lo bueno. Malebranche no parece aludir directamente a que el criterio económico de la divinidad en sus operaciones implique el Bien, siendo tal idiosincrasia expresiva tan sólo de su Sabiduría. Ahora bien, si Malebranche parece descuidar en el orden de la naturaleza y de las leyes físicas del movimiento el problema de la felicidad del género humano es porque ese asunto correspondería al orden de la gracia y al plan que el orden eterno de Dios dispone para los hombres en aras de conducirlos a todos a la felicidad por medio de Cristo y la constitución de la Iglesia. Esto último no lleva aparejado el que Malebranche descuide el orden de la creación y la naturaleza, pues, como bien señala $\mathrm{H}$. Gouhier, para Malebranche la naturaleza de los filósofos representa la más bella apología de la religión cristiana ${ }^{58}$. Si bien el orden de la naturaleza y de la gracia se rigen por los mismos criterios y parámetros en su desenvolvimiento ordinario, estos tienen causas distintas: el primero se remonta a la Sabiduría del creador; el segundo, a la Bondad y su deseo de salvación de todas sus criaturas. De ahí que Malebranche no pueda afirmar-en contraste con Leibniz-que el orden matemático y geométrico de la creación encarna la Idea del Bien.

En los últimos años el debate historiográfico se ha inclinado especialmente a tratar la diferencia que existiría en la teodicea de Malebranche entre voluntades generales y particulares. Algunos autores han señalado que la doctrina ocasionalista se revela incompatible con la declaración malebranchiana de que "Dios no actúa nunca por voluntades particulares" (Dieu n'agit point par des volontez particulières), y que, por tanto, se somete en todo momento a las leyes de la naturaleza. Los defensores de esta línea invocan asimismo el extracto de las Entretiens que dice que "Dios hace absolutamente todo por medio de las leyes naturales que él mismo dispone (...) lo que equivale a decir que Dios descansa" 59 . Frente a esto, otros autores reponen que el hecho de que Dios se acomode a esas leyes no comporta un retraimiento de su acción en el mundo. Dios “actuaría” de acuerdo con esas leyes. Las leyes no son establecidas en una fundación remota y primigenia que invalidan e inhabilitan toda intervención ulterior, sino que constituyen la sabiduría que acompañan su acción permanente sobre la naturaleza y las criaturas ${ }^{60}$. Dios no crea el mundo de acuerdo con unas leyes sabías,

58 GOUHIER, H., opus cit., p. 68.

59 Ibidem, p. 39

6o Esta línea argumentativa es desplegada por Steven Nadler en un artículo sobre la teoría de las voliciones generales en Malebranche donde aduce que la única manera de conciliar la premisa de que Dios actúa sólo a través de voluntades generales con sus convicciones ocasionalistas respecto al 


\section{REVISTA ANGELUS NOVUS}

uniformes y universales para no intervenir más sobre su creación, sino que actúa permanente sobre la misma en virtud de esas leyes que dirigen su quehacer. Las leyes son, en suma, el criterio de su obrar, nunca su obra misma. El propio Malebranche saldrá al paso de todas estas imputaciones señalando que de ningún modo entiende él por "leyes naturales" "el orden en virtud del cual las cosas son o deben ser", sino las "prácticas y siempre eficaces voliciones de su autor" ${ }^{61}$.

Nosotros estimamos que la regularidad de la intercesión divina no es el elemento clave disociador que permita dar cuenta de las diferencias sustanciales existentes entre las teodiceas de Leibniz y de Malebranche. Y es que, como se ha hecho notar en el capítulo precedente, Leibniz no pareció excesivamente preocupado por este punto, ora sugiriendo la sumisión absoluta de Dios a las leyes dictadas por su sabiduría, ora postulando su intervención continua sobre el orden de la creación. Tal es la conclusión de S. Nadler ${ }^{62}$ cuando apostilla que, a decir verdad, lo que ambos sistemas persiguen es minar la omnipotencia divina, sea mediante una necesidad metafísica (Malebranche) o moral (Leibniz) ${ }^{63}$.

¿Y si estos elementos que Nadler considera accesorios o discursivos, en tanto que, en última instancia, ambas teodiceas operan en pro de reducir la omnipotencia divina, fueran en realidad la piedra de toque de ambos sistemas? No es, en nuestra opinión, sino el carácter moral o no que los autores atribuyen a las operaciones divinas lo que nos da la clave para su debida comprensión. En Modernité et Morale (1993), C. Larmore estrecha el cerco al apuntar que, "lejos de reducirse a las mismas consecuencias prácticas, [las teodiceas de Leibniz y Malebranche] descansan sobre concepciones del todo incompatibles a propósito de la racionalidad moral de la acción divina" ${ }^{64}$. En efecto, en el Traité el teólogo francés admite que "Dios podría haber hecho, sin ningún

problema de la interacción entre cuerpo y alma-según la cual la conexión entre ambas agencias es posibilitada por la intervención permanente de Dios sobre el alma-pasa por admitir las objeciones que le planteó el teólogo jansenista Antoine Arnauld tratando de reconvertir su teoría de las "voliciones generales" en una teoría de las voliciones particulares que comparten rasgos generales (NADLER, S. "Occasionalism and General Will in Malebranche". In: Journal of the History of Philosophy, vol. 3I, pp. 3I-47, 1993).

6I PESSIN, A. "Malebranche Distinction Between General and Particular Volitons". In: Journal of the History of Philosophy, Vol. 39, n. I, pp. 95-96, 200I.

62 NADLER, S., 1994, opus cit., p. 587.

63 Nadler parece evocar aquí tácitamente la tesis-ya devenida clásica y de gran predicamento historiográfico- de P. Hazard, quien considera que, más allá de los elementos disonantes que pueden apreciarse en las teodiceas de Leibniz y Malebranche, ambas operan con idéntica audacia en el sometimiento de Dios a los hallazgos de la física y la matemática modernas. Cfr. HAZARD, P. La crisis de la conciencia europea (I680-I7I5). Madrid: Pegaso, pp. I2I-I25.

64 SCHMALTZ, T.M. "Malebranche and Leibniz on the Best of all Possible Worlds". In: Southern Journal of Philosophy, vol. 48, n.I, p. 35, 2010.

$338 \cdot$ ano XI, n. 16, $2020 \cdot$ ISSN 2179-5487 
género de duda, un mundo más perfecto que el que habitamos" "s, por cuanto "Él ama su sabiduría más que su obra" ${ }^{66}$. Adicionalmente, en su correspondencia personal con Leibniz, explicita que el mundo es el más perfecto, "no absolutamente”, sino sólo "respecto a la manera en que es realizado", ya que "Dios se honra a sí mismo no sólo por la excelencia de su obra, sino también... por la excelencia de sus medios" ${ }^{67}$.

Larmore asevera que la verdadera distinción entre Leibniz y Malebranche radica en que este último considera el bien "no sólo una cantidad que se debe producir", sino, sobre todo, "una calidad que Dios debe honrar en su obra" ${ }^{68}$. Esta tesis aún podría ser matizada. La economía y racionalidad a las que se supedita el quehacer divino no serían la forma a la que Dios acomoda su sabiduría, sino su sabiduría misma. De ello da fe la afirmación malebranchiana en el sentido de que la creación divina está presidida por una suerte de "indiferencia". Esta indiferencia es, claramente, una indiferencia de tipo moral. La subordinación a la ratio y necesidad metafísicas es igualmente exigente en la teodicea malebranchiana; sin embargo, esa ratio no se reviste de "deber moral" ni parasita la noción de lo Bueno. Esto se lo puede permitir Malebranche porque el orden matemático y geométrico de la creación, completamente subordinado a criterios racionalistas, es paralelo, pero no bomogéneo respecto al Orden eterno de Dios por el que dispone y proyecta la futura salvación y felicidad de todas sus criaturas. La Sabiduría y el Bien, la naturaleza y la gracia, van de la mano en su teodicea, sin llegar por ello a fundirse nunca en un único concepto. Cuando Malebranche afirma puntualmente que Dios "podría haber hecho un mundo más perfecto que el que efectivamente ha hecho" actuando a través de voliciones particulares, pero que no considera tal posibilidad porque su criterio de perfección ha de tener en cuenta la simplicidad de sus vías y no sólo el resultado, se prefiguran dos conceptos antagónicos de perfección: de un lado, aquel que tiene en cuenta el bien absoluto en un sentido cuantitativo; de otro, aquel en el que prima una consonancia entre el resultado y los medios empleados. Malebranche parece entender que, si Dios hubiera hecho un mundo más perfecto en arreglo a la primera acepción, ello depararía el efecto concomitante de que no fuera perfecto en esta última acepción, la cual considera, en definitiva, la más digna de los atributos divinos.

La diferencia sustantiva entre ambas teodiceas ha de buscarse, por consiguiente, en los derroteros eventualmente divergentes que trazan para la consecución de la felicidad

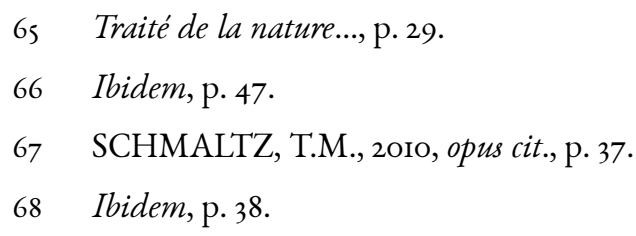




\section{REVISTA ANGELUS NOVUS}

humana. Ambos consideran que la naturaleza y sus leyes, regidas por los axiomas de la geometría y la matemática, son fielmente representativas de Dios. Con todo, los conceptos de felicidad que los autores manejan en sus respectivas teodiceas son ligeramente disímiles. Para Leibniz, la felicidad se identifica con la "felicidad de los espíritus”, es decir, la delectación que halla el intelecto al advertir que el mundo está invariablemente regido por leyes simples y racionales. Malebranche, aunque también identifica el carácter cognoscible y reducible a fórmulas y proposiciones simples de la naturaleza con la infinita sabiduría del creador, no podrá entender la felicidad únicamente como un goce intelectivo, sino más bien como el resultado de un orden y un plan que Dios alberga desde el inicio de la creación para con la humanidad, y en cuya consecución podría incluso-aunque él mismo admita que esto es muy poco probable-deponer las leyes naturales y actuar por medio de voliciones particulares. Tal vacilación no es concebible en Leibniz, en la medida en que la noción de lo bueno está ya implícita en la economía racionalista del obrar divino. La excepción implica en su teodicea el mal mismo, esto es, la constatación de una asimetría que impide dar cuenta de la identidad entre sujeto y predicado. La noción de lo bueno sirve y se subordina a las necesidades de los principios de identidad y de razón suficiente. La teodicea malebranchiana es, por lo tanto, menos racionalista en este sentido, habida cuenta de que se resiste a circunscribir la idea del bien al orden de los enunciados lógicomatemáticos y de las leyes de la naturaleza. Al filósofo y teólogo francés, el orden admirable de la razón siempre termina por conducirle invariablemente a Dios. Aunque admite el bien implícito en tales conceptos, insiste en no tomarlos en sí mismos para referirlos constantemente a Dios y al plan que este alberga para sus criaturas; todo ello frente a un Leibniz que identifica sin vacilar el bien supremo en el orden mismo de la razón, arrojando a Dios muy pronto de la ecuación.

Leibniz supeditó completamente la libertad y trascendencia divinas de la teología revelada al orden de la causalidad lógica, matemática y física, y, sobre todo, a los principios de identidad y de razón suficiente. El bien se asimila así enteramente con las necesidades de la razón. Toda noción de voluntad divina desprovista de razón o no conforme a normas toma un camino sin retorno hacia la órbita del mal. Valdría decir, pues, que Leibniz salvó la libertad divina de la necesidad spinozista sólo a costa de identificar aquélla con la maldad. Allí donde Spinoza vio lo imposible, la Natura naturans no puede producir nada distinto de la Natura naturata, Leibniz vislumbró lo máximamente indeseable, el mal mismo. Allí donde Malebranche redirigió los descubrimientos de Descartes hacia un arreglo con el cristianismo, Leibniz continuó la 
senda racionalizadora de la filosofía cartesiana de modo aún más radical, como se pone de testimonio con su concepto de mónada.

A Malebranche le urgía acomodar los descubrimientos de la filosofía moderna a una filosofía de la historia o historia de la salvación cristiana; por ello no podía operar una sencilla identificación del bien con la razón, como hiciera su coetáneo Leibniz. De modo que, bien que Malebranche no cuestiona en absoluto ninguno de los descubrimientos de la filosofía moderna (más bien todo lo contrario, pues coadyuvó a su desarrollo decisivamente con numerosos descubrimientos), se apresuró, sin embargo, a disociar el descubrimiento de Descartes de un cogito autónomo y autotrascendente para vincularlo en su lugar a la divinidad; ello le llevaría, finalmente, a disociar también la idea del bien y de la salvación de las categorías de la razón para adjudicarlas al Orden eterno que Dios diseña para el mundo, que alcanzaría su acmé con la venida de Jesucristo y el establecimiento de la Iglesia. En suma, Malebranche hace prevalecer el Orden sobre la Razón, por más que dicho Orden se acomode casi invariablemente a las prescripciones de aquélla. 